\title{
Mechanism for neurotropic action of vorinostat, a pan histone deacetylase inhibitor
}

Surabhi Shukla ${ }^{1,2}$, Zia Shariat-Madar ${ }^{2}$, Larry A Walker ${ }^{1,2}$ and Babu L. Tekwani ${ }^{1,2}$

${ }^{1}$ National Center for Natural Products Research and ${ }^{2}$ Department of BioMolecular Sciences, School of Pharmacy, University of Mississippi, University MS 38677

Correspondence to: Babu L. Tekwani, National Center for Natural Products Research, School of Pharmacy, University of Mississippi, University MS, 38677 USA; Phone: 662-915-7882; Email: btekwani@olemiss.edu

Keywords: Histone deacetylase, vorinostat, suberoylanilohydroxamic acid, neurotrophic, neuritogenesis, PC12 cells; Phosphoinositide 3-kinase, MAPK

Running title- Neurotrophic action of vorinostat on NS-1 cells 

Abbreviations:
BDNF Brain - derived neurotrophic factor
cAMP Cyclic Adenosine Monophosphate
CTCL Cutaneous T-cell lymphoma
DMSO Dimethyl sulfoxide
ECL Enhanced chemiluminescence
ERK Extracellular- signal regulated- kinase
GDNF Glial cell line-derived neurotrophic factor
HATs Histone acetyl transferases
HD Huntington's disease
HDAC Histone deacetylases
HDACi Histone deacetylase inhibitors
MEK Mitogen/Extracellular -signal -regulated Kinase
NGF Nerve growth factor
NS-1 Neuroscreen -1
PBS Phosphate -buffer saline
PC12 Pheochromocytoma cells
PI3K Phosphatidylinositide 3-kinases
PKA Protein kinase A
PLC Phospholipase c gamma pathway
SAHA Suberoylanilide Hydroxamic Acid
SMA Spinal Muscular atrophy
TBST Tris buffer saline with tween 20
TrkA Tyrosine receptor kinase A
VPA Valproic acid 


\begin{abstract}
In this study we investigated the neurotrophic actions of vorinostat (suberoylanilide hydroxamic acid, SAHA), a class I and class II HDAC inhibitor, on the differentiation of Neuroscreen-1 (NS1) cells. NS-1 cell is a subclone of the rat pheochromocytoma cell line (PC 12). Vorinostat independently induced neurite outgrowth in NS-1 cells. The NS-1 cells were further interrogated for the effects of vorinostat on intracellular neurotrophin signaling pathways, to understand its mechanism of neurotrophic action. Selective inhibitors of MEK1/2 (PD98059 and U0126), phosphoinositide 3-kinase (PI3K) (LY294002) and tyrosine kinase A (TrkA) (GW441756) were employed for these interrogations. Our results suggest that neurite outgrowth mediated by both nerve growth factor (NGF), an intrinsic neurotrophin, and vorinostat were blocked by the inhibitors of MEK1/2 \& PI3K. Vorinostat induced phosphorylation of ERK1/2 occurs at 2 hours post treatment. Phosphorylation of ERK was abolished in presence of U0126, further confirming the role of ERK pathway in vorinostat-induced differentiation of NS-1 cells. Vorinostat-induced neurite outgrowth also involves the activation of upstream extracellular kinase TrkA, as both vorinostat mediated neurite outgrowth and activation of ERK were attenuated in presence of the TrkA inhibitor, GW441756. Vorinostat also stimulated hyperacetylation of $\alpha$-tubulin and histones H3/H4 in NS-1 cells. The results suggest that vorinostat exerts a positive effect on the neuritogenesis via activation of MEK1/2 \& PI3K pathways involving an upstream kinase, TrkA. Bioactive small molecules with neurotrophic and neuritogenic actions, like vorinostat identified in the present study, hold great promise as therapeutic agents for treatment of neurodegenerative diseases and neuronal injuries by virtue of their ability to stimulate neuritic outgrowth.
\end{abstract}




\section{Introduction}

Neuritogenesis, formation of neurites by neuronal cells, is the initial step in the development of a mature neuronal morphology (Dotti et al., 1988; Craig and Banker, 1994). The key morphological features of neuritogenesis include branching of neurites followed by elongation of axons and branching of dendrites (Kiryushko et al., 2004). Neurite outgrowth is a vital event in neuronal development. It also plays an important role in formation, and remodeling of synapses, response to injury, and regeneration. Thus, understanding the mechanism of neurotrophic processes like neurite outgrowth and neuronal survival is crucial for studies related to brain development, pathophysiology and treatment of various neurodegenerative disorders like Alzheimer's and Parkinson's diseases (Kaplan et al., 1997).

Neurotrophic factors have been extensively studied with regard to their role in neuronal development and synaptic plasticity. In in vivo and in vitro studies, neurotrophic factors have been shown to promote neurite outgrowth, neuronal differentiation, proliferation, survival, and regeneration (Takano et al., 2002; Munno et al., 2000; Schinder et al., 2000). However, as treatment modalities, neurotrophic factors are large polypeptide molecules and have limited permeability across the blood brain barrier. Also, they are easily metabolized by peptidases, which pose the greatest barrier for their therapeutic application (Maruoka et al., 2011). Therefore, the small molecule neurotrophic compounds that can mimic the functions of intrinsic neurotrophic factors could serve as good alternates for therapeutic use in treatment of neurodegenerative diseases and neuronal injuries (More et al., 2012; Longo and Massa, 2013).

Recent reports have demonstrated neuroprotective and neuroactive properties of small molecular weight inhibitors of histone deacetylases (HDACs) and their potential use in treatment of neurological disorders (Camelo et al., 2005; Wiech et al., 2009; Xu et al., 2011). HDACs catalyze the removal of acetyl groups from histones and non-histone proteins and are major epigenetic regulators (Hildmann et al., 2007). Within the last decade, many studies have demonstrated neuroprotective effects of HDAC inhibitors (HDACi) (Chuang et al., 2009). HDACi are recognized as potential anticancer agents (Slingerland et al., 2014; Bose et al., 2014) and also play important role in inducing neurite outgrowth and neuroprotection (Xu et al., 2011). In diseased neurons, $\mathrm{HDACi}$, by reducing histone deacetylation, can restore transcriptional balance and thereby delay or stop cellular degeneration. It is considered that neurotrophic activities of HDACi might be epigenetically controlled by acetylation of histone as well as nonhistone proteins such as transcription factors (Sterner and Berger, 2000). During neuronal development in the peripheral nervous system, regulation of transcription by epigenetic modifications has been reported to play an important role in neurite outgrowth and neuroprotection (Guab et al., 2010). Evidence for a neuroprotective role of HDACi has been developed in experimental models of various neurodegenerative diseases such as Huntington Disease (Gardian et al., 2005), amyotrophic lateral sclerosis (Petri et al., 2006), and multiple sclerosis (Camelo et al., 2005). However, the precise mechanisms of the neuroprotection are not clearly understood.

Initial screening of a battery of pan and selective HDACi identified prominent neurotrophic action of vorinostat (suberoylanilide hydroxamic acid, Zolinza ${ }^{\mathrm{TM}}$ ) in NS-1 cells. NS-1 cells are a subclone, derived from rat pheochromocytoma cell line (PC 12), which has ben extensively used as model cells for neuronal differentiation and neurosecretion (Vaudry et al, 2002; Westerink and 
Ewing, 2002). Vorinostat is a broad spectrum HDACi that inhibits zinc-dependent HDACs (Class I, II and IV). It can induce growth arrest in transformed cells and shows promise for the treatment of cancer. Vorinostat received FDA approval for use in cutaneous T-cell lymphoma (CTCL), and is in clinical trials for number of other malignancies (Glaser et al., 2007). Vorinostat specifically binds to and inhibits the activity of histone deacetylases, resulting in acetylation of nucleosomal histones and an activation of gene transcription (Munster et al., 2001). The neuroptrotective effect of vorinostat has been tested in many neurodegenerative disease models such as Huntington's Disease (HD) and spinal muscular atrophy (SMA) models. Vorinostat was shown to improve motor impairment in R6/2 transgenic mouse model of HD (Hockly et al., 2003) and it significantly enhanced motor function abilities and life spans of SMA mice by reducing the degeneration of motor neurons (Riessland et al., 2010).

Considering the possible neuroprotective and neurotrophic role of the HDACi, the primary aim of this study was to examine the potential of vorinostat in modulating neuritogenesis in NS-1 cells, and to interrogate the underlying cellular and molecular mechanisms involved. Our results show that vorinostat is capable of independently inducing neuritogenesis in NS-1 cells through activation of MAPK-ERK pathway, which involves activation of upstream kinase TrkA. Treatment of NS-1 cells with vorinostat also induces hyperacetylation of $\alpha$-tubulin and histones $\mathrm{H} 3$ and $\mathrm{H} 4$.

\section{Material and Methods}

Vorinostat was purchased from Selleck Chemicals (selleckchem.com, Houston, USA). The MAPK signaling pathway inhibitor U0126, MEK1/2 specific inhibitor (PD89059), and PI3K inhibitor (LY294002) were purchased from Cell Signaling Technology, Danvers, USA. TrkA inhibitor (GW441756) was purchased from Selleck Chemicals, Houston, USA. Nerve Growth Factor (NGF 2.5s), purified from mouse submaxillary glands was purchased from BD Bioscience, San Jose, USA. p44/42MAPK(ERK1/2)Thr202/Tyr204 antibody; p44/42MAPK( ERK1/2) antibody, anti-rabbit HRP-conjugated IgG secondary antibody, Acetyl- Histone H3 (Lys 9) antibody, Acetyl Histone H4 (Lys 8) antibody, Histone H3 antibody, Histone H4 antibody, Acetyl $\alpha$-tubulin (Lys 40), $\alpha$-tubulin antibody , antibody- $\alpha$-Tubulin (Lys40) (D20G3) $\mathrm{XP} \circledast$ and Anti rabbit IgG $(\mathrm{H}+\mathrm{L}), \mathrm{F}\left(\mathrm{ab}^{\prime}\right) 2$ Fragment( Alexa Fluor 488 Conjugates) and cell lysis buffer were purchased from Cell Signaling Technology, USA. Bradford protein assay reagent was obtained from Bio-Rad and enhanced chemiluminescence (ECL) detection kit was purchased from GE Healthcare, USA.

\subsection{Cell Culture}

PC12 is a widely used cell line derived from rat pheochromocytoma cells that serves as a useful model for studying neurite outgrowth or neurotransmitter release (Green 1982). PC12 cells display an important feature, in that when treated with NGF, they undergo a dramatic change in phenotype and acquire number of characteristic properties of sympathetic neurons. NGF-treated PC12 cells stop proliferation and start differentiation by extending neurites, and become electrically excitable (Greene 1982). The NS-1 clone was chosen as these cells have improved adherence, shorter doubling times and higher responsiveness to the NGF (Dijkmans et al., 2008). NS-1 cells were procured from Cellomics Inc, USA, maintained in culture flasks coated with 
collagen IV, in culture medium consisting of RPMI 1640 supplemented with $10 \%$ horse serum, $5 \%$ fetal bovine serum, $2 \mathrm{mM}$ glutamine and $100 \mu \mathrm{g} \mathrm{mL} \mathrm{m}^{-1}$ of penicillin/streptomycin (pen/strep) at $37^{\circ} \mathrm{C}, 5 \% \mathrm{C} 02$ and $90 \%$ humidity. The cells were sub cultured once every week.

\subsection{In vitro cytotoxicity}

NS-1 cells were seeded onto a collagen IV coated clear 96 well plate (BD Biosciences) with 2000 cells/well. The cells in RPMI-1640 growth medium were allowed to adhere onto the plate surface for 24 hours. The cultures were treated with specified concentrations of vorinostat, NGF and other signaling inhibitors as specified for 72 hours. For evaluation of cytotoxicity of these treatments, $20 \mu \mathrm{l}$ of the alamarBlue reagent was added directly to the media into each well at 48 hours time point. Plates were further incubated for 24 hours. The fluorescence was measured at $544 \mathrm{~nm}$ excitation and 590nm emission using a microplate reader and the data were analyzed to determine viability/cytotoxicity. The alamarBlue is non-toxic; measures cell viability, growth \& proliferation.

\subsection{Neuritogenesis Assay}

After reading the plates for cell viability, plates were washed with phosphate-buffered saline (PBS), fixed with methanol and stained with Giemsa for 1 hour. Giemsa stain was purchased from Sigma Aldrich, St. Louis, Missouri, USA. It is a differential stain that stains nucleus and cytoplasm differentially. Before staining of cells, a 1:40 dilution of Giemsa stain was prepared in deionized water and $150 \mu \mathrm{l}$ of the diluted stain was added into the wells of 96 well plate and cells were allowed to stain for 1 hour. The plates were rinsed with deionized water, air-dried and subjected to digital imaging under a bright light microscope for measurement of neuritogenesis. At least three images were captured from each well. Representative photomicrographs were captured with a Nikon digital camera attached to the microscope using 10X objective and the image were stored as JPEG files. Three fields per well were selected randomly and images were captured. 50 cells per field with three wells per treatment were analyzed. The experiments were performed three times. Cells exhibiting processes longer than two times the diameter of the cells were scored as positive for neurite outgrowth. Neurite length was calculated by tracing the neurites in each cell by computer mouse using Nikon NIS element software. Mean neurite length and number of neurites were calculated from number of cells (50) counted .The data obtained were exported to an MS Excel file. The values from the MS Excel file were copied and pasted into a macro-based MS Excel template, which was designed to measure neurite outgrowth. The neuritogenesis was assessed according to the following parameters: (a) mean neurite length (ratio between sum of length of total neurites measured to the number of neurites measured); (b) neurite length/cell (ratio between sum of length of total neurites measured to the number of cells counted); (c) neurites/cell (total number of neurites/ number of cells counted).

To evaluate the signaling pathways involved in vorinostat induced neuritogenesis, cell cultures were pretreated with $10 \mu \mathrm{M}$ MEK1/2 inhibitors (PD98059 and U0126) or $10 \mu \mathrm{M}$ PI3K inhibitor (LY294002) or TrkA inhibitor GW441756 $(1 \mu \mathrm{M})$ for 1 hour, followed by treatment with vorinostat $(1 \mu \mathrm{M})$ and/or NGF $\left(2.5 \mathrm{ng} \mathrm{mL}^{-1}\right)$ (positive control) for an additional 72 hours. DMSO (final concentration 2.5\%) was used as the negative control in each assay. Cytotoxicity and neuritic outgrowth assays were conducted as described above. 


\subsection{Analysis of phosphorylation of ERK1/2 by Western blotting}

NS-1 cells $\left(2.5 \times 10^{5}\right.$ cells $\left.\mathrm{mL}^{-1}\right)$ were seeded onto collagen coated $75 \mathrm{~cm}^{2}$ cell culture flasks and allowed to adhere for 24 hours. At least two $75 \mathrm{~cm}^{2}$ cell culture flasks were set up for each treatment. Cells were pre-treated with U0126 $(10 \mu \mathrm{M})$ for 1 hour, followed by treatment with vorinostat $(1 \mu \mathrm{M})$ and/or NGF $\left(2.5 \mathrm{ng} \mathrm{mL}^{-1}\right)$ with and without U0126 for 5, 15, 30, 60 and 120 minutes. Two control flasks were set-up with DMSO $(0.25 \%)$ for each set of assay. For TrkA inhibitor experiment, cells were pre-treated with GW441756 $(1 \mu \mathrm{M})$ for 1 hour and then the cells were treated with vorinostat $(1 \mu \mathrm{M}$ and $2.5 \mu \mathrm{M})$ for 3 hours with and without inhibitors. The treated and untreated cells were harvested at specified time points and lysates were prepared using $1 \mathrm{X}$ cell lysis buffer. Protein concentrations in the lysates were determined with the Bradford protein assay kit (Bio-Rad USA). Equal amounts $(20 \mu \mathrm{g})$ of proteins (unless otherwise noted) were loaded into the wells of $10 \%$ SDS-PAGE mini gels (Bio-Rad, USA), electrophoresed and proteins were transferred to nylon membranes following the Cell Signaling Technology (USA) protocol for Western blotting. Membranes were blocked in 5\% nonfat dried milk in 1x TBST [20 mM Tris- $\mathrm{HCl}(\mathrm{pH} 7.5), 137 \mathrm{mM} \mathrm{NaCl}$ and $0.1 \%(\mathrm{v} / \mathrm{v})$ Tween 20] for 1 hour at room temperature. Blots were probed overnight with phosph-p44/p42MAPK (ERK1/2) antibody (for measuring phosphorylated ERK1/2) and p44 MAPK (ERK1) antibody for total ERK levels following the manufacturer's protocols. For primary antibody, dilution used was 1:1000. Antibody against $\beta$-actin was used to confirm equal loading of the protein samples. The membranes were washed with 1x TBST and probed with anti-rabbit secondary antibody conjugated to HRP (1:2000 dilution) for 1 hour. The blots were developed with enhanced chemiluminescence (ECL) kit. The digital images were captured, processed and analyzed on Bio-Rad ChemiDoC MP imaging system. Densitometry analysis of immunoblots were performed using ImageJ v1.50i

\subsection{Analysis of acetylation of $\alpha$-tubulin, histones $H 3$ and $H 4$}

For detecting acetylation of $\alpha$-tubulin, NS-1 cells were treated with vorinostat for 8 and 24 hours and protein extracts were probed with antibody against acetylated alpha-tubulin (Lys 40). For analysis of acetylated histones $\mathrm{H} 3$ and H4, NS-1 cells were treated with vorinostat ( $1 \mu \mathrm{M}$ and $2.5 \mu \mathrm{M}$ ) for 24 hours. Since it was short time incubation up to 24 hours, vorinostat at $2.5 \mu \mathrm{M}$ was also tested. The extracts were from treated and untreated cells and analyzed by the Western blot. $20 \mu \mathrm{g}$ of lysate were probed with antibodies against acetyl-histone H3 (Lys 9) and acetyl- histone H4 (Lys 8). Detection was done using ECL chemiluminescence kit. Densitometry of immunoblots was done using Image J v1.50i.

\subsection{Immunostaining NS1 cells for acetylated $\alpha$-tubulin.}

NS-1 $\left(1 \times 10^{5}\right)$ cells were seeded onto Ibidi microchamber collagen IV coated 4 well plastic slides. The cells were allowed to adhere for 24 hours. Next day, the cells were treated with vorinostat $(1 \mu \mathrm{M})$ or NGF $\left(2.5 \mathrm{ng} \mathrm{mL}^{-1}\right)$ for 8 hours. The medium was aspirated, cells were treated with $400 \mu \mathrm{L}$ of $4 \%$ paraformaldehyde diluted in warm PBS. Cells were allowed to fix for 15 minutes at room temperature. The fixative was aspirated and the cells were washed three times with 1X PBS. The slide was processed further for immunostaining. Blocking was done 
with the blocking buffer (1X PBS/5\% normal serum $/ 0.3 \%$ Triton $\left.^{\mathrm{TM}} \mathrm{X}-100\right)$ for 60 minutes. After 1 hour the blocking solution was aspirated and cells were treated with primary antibody $\alpha$ tubulin (Lys40) (D20G3) XP® (1:800 dilution) in the dilution buffer (1X PBS/1\% BSA/0.3\% Triton $\left.^{\mathrm{TM}} \mathrm{X}-100\right)$. The slides were incubated overnight at $4^{\circ} \mathrm{C}$ and rinsed three times with $1 \mathrm{XPBS}$ for 5 minutes each. The cells treated with primary antibody were further treated with fluorochrome-conjugated secondary antibody (Anti rabbit IgG $(\mathrm{H}+\mathrm{L}), \mathrm{F}(\mathrm{ab}$ ') 2 Fragment (Alexa Fluor 488 Conjugates), diluted 1:1000 in the antibody dilution buffer, for 2 hours at room temperature in the dark. The slides were rinsed 3 times with 1XPBS. The cells were stained with $300 \mu \mathrm{L}$ DAPI (4', 6-diamidino-2-phenylindole), a nuclear staining dye and rinsed 3 times with 1XPBS for 5 minutes each. The cells were mounted with DABCO (2\% DABCO, 80\% glycerol in PBS), and examined under the confocal microscope Zeiss 510 and filters used were 420-480, 505-550, or 560-615

\subsection{Statistical analysis}

All quantitative data are presented as mean and standard errors as computed with MS Excel and GraphPad Prism 6 software. One-way analysis of variance (ANOVA) followed by Bonferroni test was used to compare multiple groups. The $\mathrm{p}$ values were computed to determine statistically significant differences among the groups. $\mathrm{P}$ values $<0.05$ were considered as statistically significant.

\section{Results}

\subsection{Vorinostat independently stimulates neuritogenesis in NS-1 cells}

We tested three concentrations of vorinostat $(1,2.5$ and $5 \mu \mathrm{M})$ to assess its neurotrophic action on the NS-1 cells. Vorinostat was significantly cytotoxic to NS-1 cells at 2.5 and $5 \mu \mathrm{M}$, and non-toxic at $1.0 \mu \mathrm{M}$ concentrations as compared to the untreated control cells (Figure1). In figure $1, \mathrm{X}$ axis represents the concentration of vorinostat tested and $\mathrm{Y}$ axis has growth expressed as a $\%$ of control. Fluorescence intensity value of control is considered as $100 \%$, which is expressed as ratio of fluorescence intensity at 560 excitation and 590 emission of control cells to control cells multiplied by 100 . The percent growth of vorinostat treated cell is calculated as ratio of fluorescence intensity of treated cells to control cells, multiplied by 100 (Figure 1). A dose response curve for NGF, the intrinsic neurotrophin, mediated neurite outgrowth was established. NGF (1.25-10 ng / $\mathrm{mL}^{-}$) was found to cause a dose-dependent stimulation of neuritic outgrowth in NS-1 with no effect on viability of the NS-1 cells. In subsequent studies, NS-1 cells were treated with vorinostat $1 \mu \mathrm{M}$ and/or NGF $(2.5 \mathrm{ng} / \mathrm{mL})$ for 72 hours to investigate their neurotrophic actions. Vorinostat (SAHA) at $1 \mu \mathrm{M}$ concentration, independent of NGF, stimulated significant neurite formation in NS-1 cells (Figure 2A) compared to control cell culture. The neuritic outgrowth induced by vorinostat was comparable to the effect of NGF. The induction of neuritic out growth in NS-1 cells by combination of vorinostat and NGF was similar to that produced by the NGF alone. Further, the neurite outgrowth in NS-1 cells was quantitatively measured and presented as three end points namely, mean neurite length (Figure 2B), numbers of neurites/cell (Figure 2C) and neurite length/cell (Figure 2D). The independent and significant neurotrophic action of vorinostat was confirmed based on significant increase in all three parameters, namely, mean neurite length, numbers neurites/cell and neurite length/cell. 
Neuritogenesis induced by vorinostat was marginally less prominent as compared to NGF induced neuritogenesis. Vorinostat in combination with NGF had a similar effect on neurite outgrowth as NGF treatment alone. Which implicates the measured parameters analyzed for measuring neurite outgrowth i.e. mean neurite length, number of neurites/cell and neurite length /cell in NGF alone and vorinostat and NGF combined cells did not significantly differ statistically.

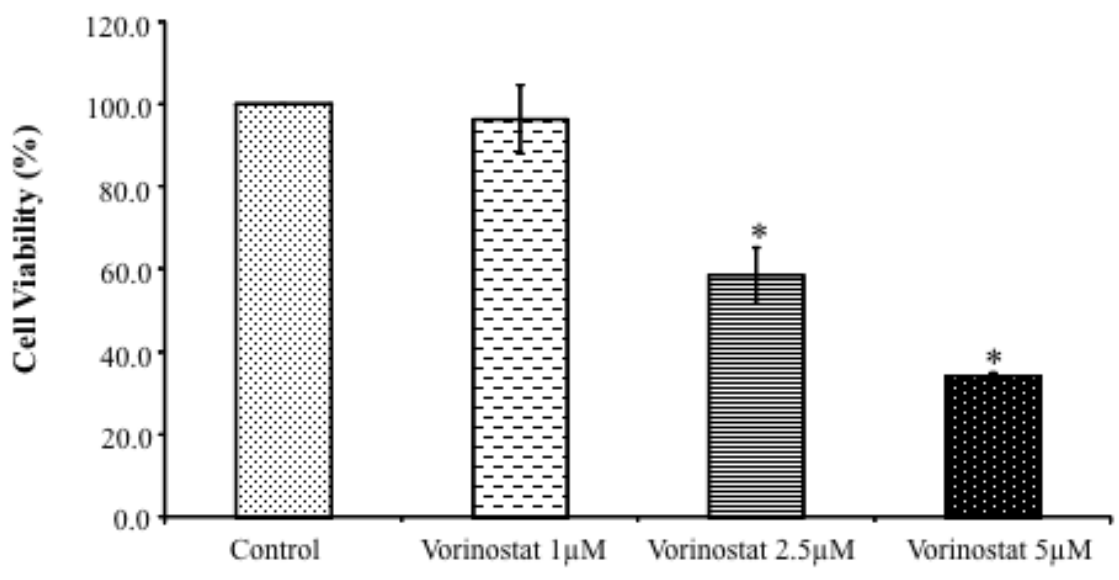

Figure 1 Effect of vorinostat on growth and viability of NS-1 cells. The values on Y-axis present the \% viability as compared to control. Neuroscreen-1 cells were treated with $0.25 \%$ DMSO (Control) and vorinostat (concentrations as specified) for 72 hours. At 48 hours, viability was measured using alamarBlue assay. Data represented are mean $\pm \mathrm{SE}$ of three independent experiments. Data were analyzed using one-way ANOVA followed by Bonferroni test for multiple comparisons (Values compared to control vs vorinostat 1, 2.5 and $5 \mu \mathrm{M})$. $* \mathrm{P}<0.05$ shows significant difference. 
A
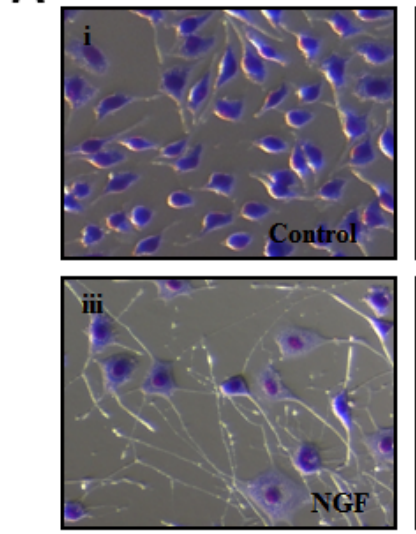

C

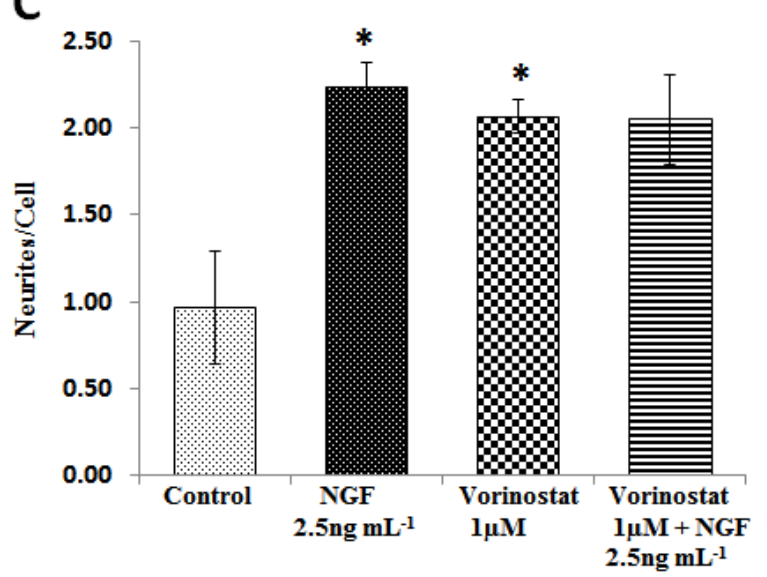

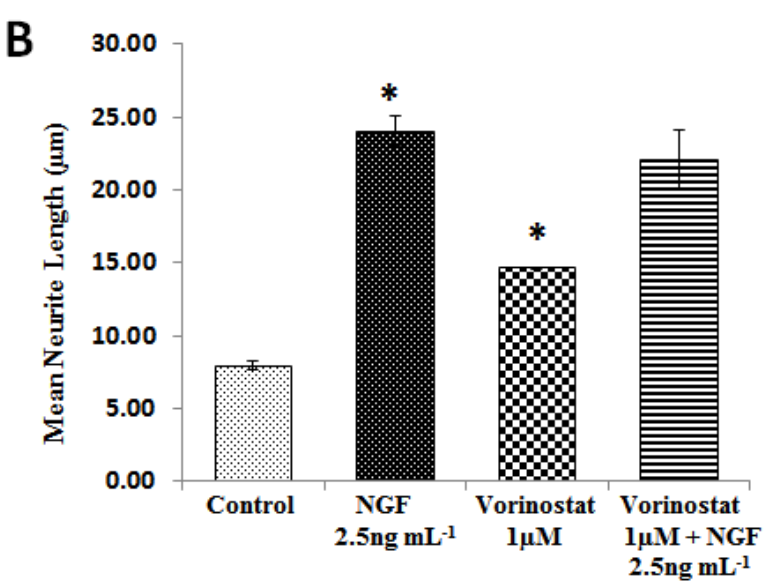

D

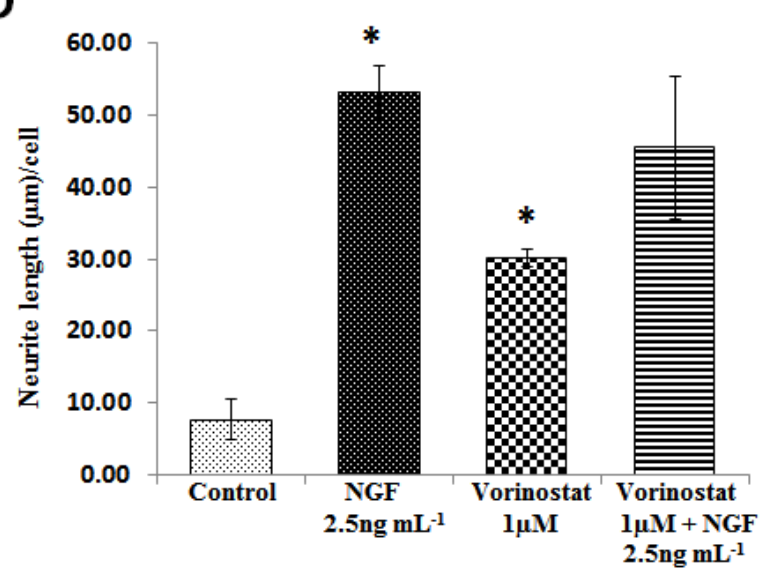

Figure 2. Induction of neurite outgrowth in NS-1 cells by vorinostat treatment. [A] Microscopic digital images of NS-1 cells (i) Control NS- 1 cells (ii) NS-1 cells treated with 1 $\mu \mathrm{M}$ vorinostat for 72 hours. (iii) NS-1 cells treated with NGF $(2.5 \mathrm{ng} \mathrm{mL})$ for 72 hours (positive control). (iv) NS-1 cells treated with vorinostat $(1 \mu \mathrm{M})+\mathrm{NGF}\left(2.5 \mathrm{ng} \mathrm{mL}^{-1}\right)$. Neurite outgrowth /neuritogenesis was measured in terms of three end points namely, [B] mean neurite length [C] numbers of neurites/cell and [D] neurite length/cell. Data represented are mean \pm SE of three independent experiments. Data were analyzed using One way ANOVA followed by Bonferroni test for multiple comparison (Values compared to control vs NGF, vorinostat and NGF Vs vorinostat, NGF Vs vorinostat with NGF) . $* 000$ shows significant difference.

\subsection{Vorinostat induced neurite outgrowth is attenuated by inhibitors of MEK PI3K pathways}

To understand the mechanism of action of vorinostat-mediated neuritogenesis, the neurotrophic action of vorinostat was tested in the presence of selective inhibitors of MEK (ERK1/2) and PI3K, which are known to be involved in NGF-mediated neurotrophic actions. The cell cultures were pretreated with the selective inhibitors of MEK1/2 (PD98059 and U0126) and PI3K (LY294002) for $1 \mathrm{hr}$, followed by treatment with vorinostat $(1 \mu \mathrm{M})$ and/or NGF $(2.5$ ng $\mathrm{mL}^{-1}$ ) (positive control). $0.25 \%$ DMSO was tested as a negative control. Cytotoxicity of these inhibitors was also measured at 72 hours post-treatment and cells were further analyzed for 
neuritic outgrowth by neuritogenesis assay as described above. None of the treatments have significant effect on viability of NS-1 cells, as measured by the alamarBlue assay. The percent cell viability for each inhibitors tested was in the range of $85-95 \%$ as compared to control (Figure 3D). We found that MEK inhibitors U0126 and PD98059 and PI3K inhibitor significantly reduced NGF-induced neurite outgrowth in NS-1 cells as indicated by significant decrease in mean neurite length, neurites/cell and neurite length/cell (one way ANOVA and Bonferroni's multiple comparison test, $\mathrm{p} \leq 0.05$ ). Similarly, vorinostat induced neuritogenesis was also significantly attenuated by PD98059, U0126 (MEK1/2 inhibitors) and LY294002 (PI3K inhibitor) as determined by significant decrease in mean neurite length (Figure 3A) neurites/cell (Figure 3B) neurite length/cell (Figure 3C) (one way ANOVA and Bonferrroni's multiple comparision test to compare NGF, Vorinostat, and control, $\mathrm{p} \leq 0.05$ ). These observations indicate involvement of MAP Kinase pathway and to some extent PI3K pathway in neurotrophic action of vorinostat. Cells treated with U0126 alone did not show any neurite outgrowth suggesting that basal level of neurite outgrowth in the cell is also affected by U0126.
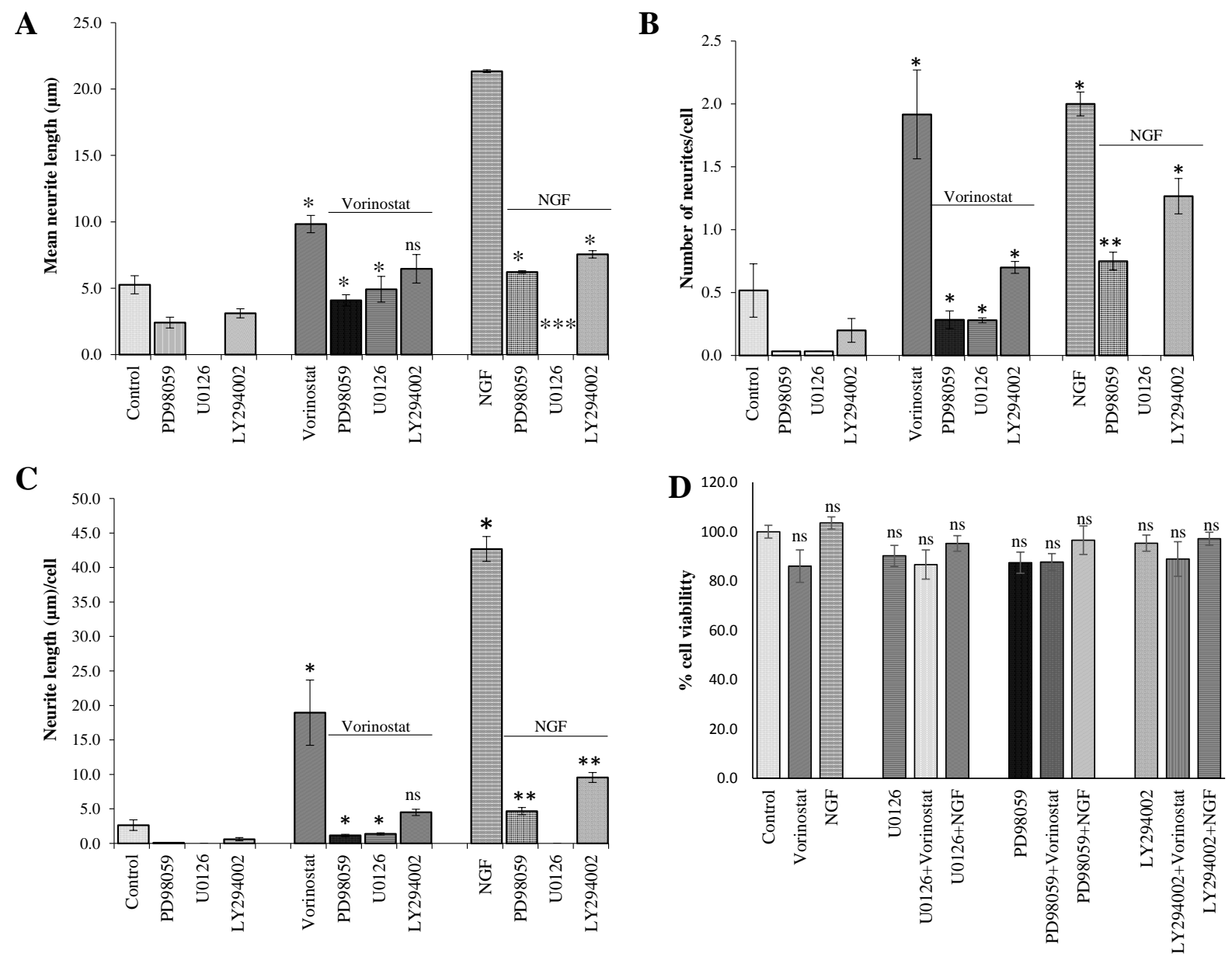

Figure 3. Vorinostat induced neuritogenesis in NS-1 cells is dependent on activation of MEK. NS-1 cells were treated with $1 \mu \mathrm{M}$ Vorinostat, $2.5 \mathrm{ng} \mathrm{mL}^{-1} \mathrm{NGF}$, and/or $10 \mu \mathrm{M}$ MEK1/2 inhibitors (PD98059 and U0126) and 10 $\mu$ M PI3K inhibitor (LY294002) for 48/72 
hours and assayed for cytotoxicity and neurite outgrowth. Quantification was performed for following parameters. [A] Mean neurite length: ratio between total neurites length and number of cells counted. [B] Neurites/cell: ratio between number of neurites and number of cells counted and [C] neurite length/cell: ratio between total neurites length and number of cells counted. [D] Effect of U0126, PD98059 and LYK294002 in combination with vorinostat and NGF on viability of NS-1 cells. The values on Y-axis present the \% viability as compared to control. The data sets are the mean $\pm \mathrm{SE}$ of three independent experiments. Data were analyzed using one way ANOVA followed by Bonferroni test for multiple comparison (Values compared with control vs NGF and vorinostat, NGF and vorinostat treated cells vs inhibitor in combination with vorinostat and NGF $* \mathrm{P}<0.05$, ** $\mathrm{P}<0.001$, $* * * \mathrm{P}<0.0001$, ns indicates non-significant difference

3.3 Vorinostat treatment activates phosphorylation of ERK1/2 in NS-1 cells, which is attenuated in presence of $U 0126$.

To further confirm the involvement of MEK pathway in the neurotrophic action of vorinostat, we tested the ability of vorinostat to activate ERK by measuring its phosphorylation. Both vorinostat $(1 \mu \mathrm{M})$ and NGF $\left(2.5 \mathrm{ng} \mathrm{mL}^{-1}\right)$ treatments produced a time-dependent activation of phosphorylation of ERK (Figure 4). NGF was able to stimulate high levels of ERK phosphorylation in NS-1 cells within 5 minutes of treatment, which still remained highly phosphorylated until 120 minutes post-treatment. In case of vorinostat, the noticeable activation of ERK phosphorylation could be noticed only after 60 minutes of the treatment, a relatively delayed response as compared to NGF. Vorinostat-induced significant phosphorylation of ERK at 120 minutes time point (Figure 4 A\&B). Further, co-treatment of NS-1 cells with vorinostat and U0126, the MEK1/2 inhibitor, resulted into complete inhibition of ERK phosphorylation, which was significant (Figure 4B). NGF induced ERK phosphorylation was also significantly abolished by U0126 for all the time points studied (Figure 4B). Taken together, the results demonstrate that vorinostat activates the ERK pathway in NS-1 cells, which leads to induction of neuritic out growth in NS-1 cells.
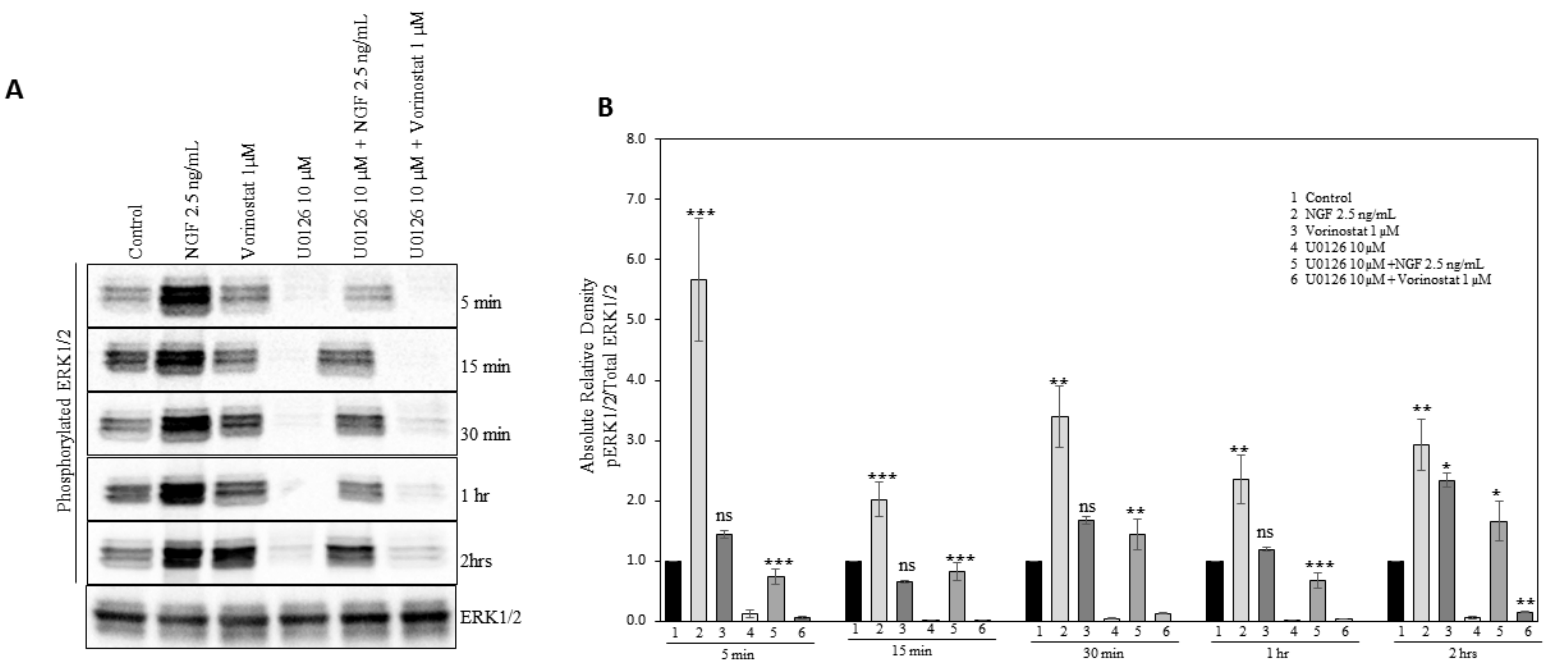
Figure 4. Vorinostat and NGF induced ERK1/2 phosphorylation in NS-1 cells is attenuated by co-treatment with U0126 (the inhibitor of ERK1/2 phosphorylation). A) NS-1 cells were treated with $1 \mu \mathrm{M}$ vorinostat and $\left(2.5 \mathrm{ng} \mathrm{mL}^{-1}\right) \mathrm{NGF}$ with and without $10 \mu \mathrm{M}$ U0126 for 5, 15, 30, 60 and 120 minutes. Cell extracts were prepared. The extract ( $20 \mu \mathrm{g}$ protein of each) were subjected to SDS-PAGE and immunoblotted with p44/42MAPK (ERK1/2)Thr202/Tyr204 antibody for phosphorylated ERK; p44/42MAPK(ERK1/2) antibody for total ERK level and anti $\beta$-actin antibody for detecting total $\beta$-actin. B) Bar graph represents the densitometric analysis of immunoblots. $\mathrm{X}$ axis represents treatments $\mathrm{Y}$ axis represents the ratio of absolute relative density of $\mathrm{pERK}$ to the total ERK. The data sets are the mean $\pm \mathrm{SE}$ of two biological replicates from two independent experiments (Values compared to Control vs NGF, control vs vorinostat, NGF Vs U0126+NGF and Vorinostat Vs U0126+NGF. Data were analyzed using one way ANOVA followed by Bonferroni test for multiple comparison. $* \mathrm{P}<0.05$, $* * \mathrm{P}<0.001$, $* * * \mathrm{P}<0.0001$ values indicate significant differences and ns indicates non-significant difference.

\subsection{Vorinostat mediated neurite outgrowth is dependent on upstream kinase TrKA}

As vorinostat induced neurite outgrowth required activation of ERK, we hypothesized that it may involve the upstream kinase TrkA like NGF mediated neurite outgrowth. To check our hypothesis vorinostat mediated neuritogenesis was evaluated in the presence of TrkA tyrosine kinase inhibitor (GW441756). The NS-1 cells were pretreated for 1 hour with GW441756 (1 $\mu \mathrm{M})$. Followed by treatment with vorinostat and NGF. NS-1 cell treated with GW441756 and NGF was used as a positive control. After 72 hours treatment, cells were stained with Geimsa and neurite measurement was done using NIS element software. Endpoints measured were mean neurite length and neurite length/cell. There was a significant reduction (one way ANOVA followed by Bonferroni multiple comparision test, $\mathrm{p} \leq 0.05$ ) in neurite outgrowth measured in terms of mean neurite length (figure 5A) and neurite length/cell (figure 5B) in vorinostat treated cells in the presence of TrkA inhibitor, GW441756. This suggests that vorinostat mediated neuritogenesis involves activation of upstream TrkA receptor. 
A

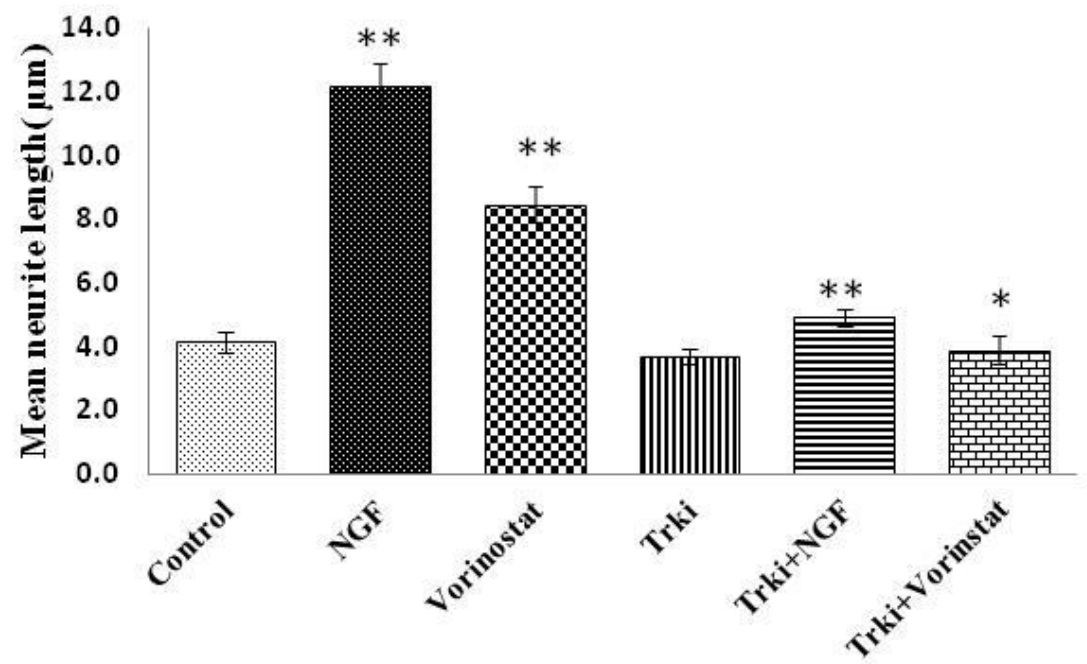

\section{B}

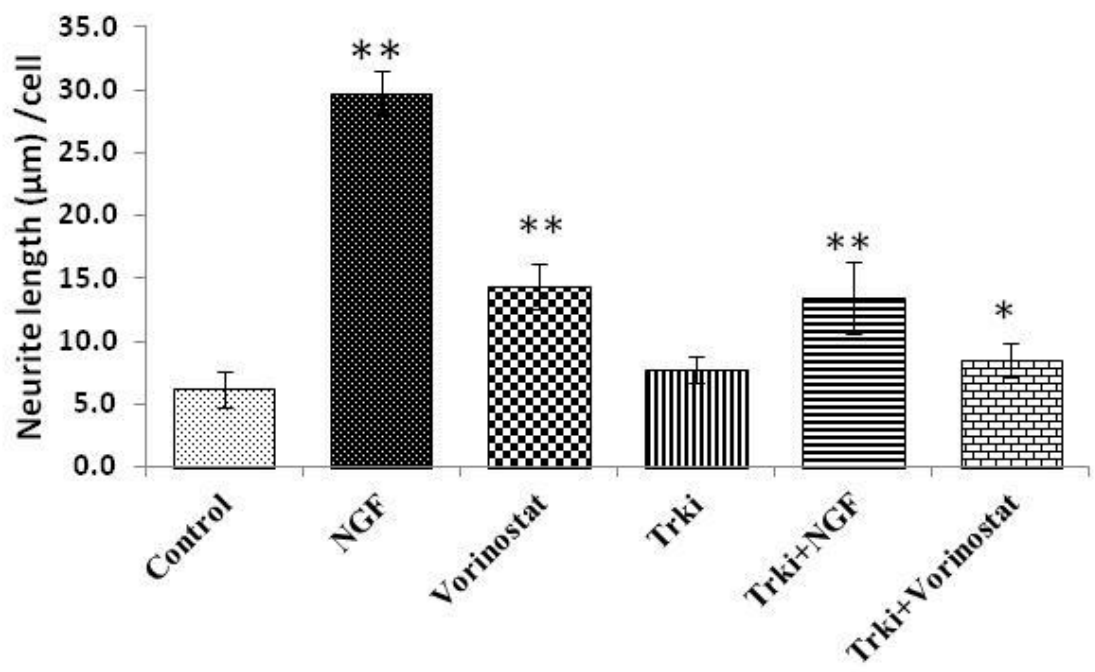

Figure 5. Vorinostat induced neuritogenesis in NS-1 cells is dependent on activation of upstream kinase TrkA. Vorinostat mediated neurite outgrowth in NS-1 cells is reduced in presence of TrkA inhibitor GW441756. NS-1 cells were pre-treated with $1 \mu \mathrm{M}$ GW441756 for 1 hour then 1 $\mu \mathrm{M}$ Vorinostat and $2.5 \mathrm{ng} \mathrm{mL}^{-1} \mathrm{NGF}$, were added for 72 hours and assayed for neurite outgrowth. Quantification was performed for following parameters. [A] Mean neurite length: ratio between total neurites length and number of cells counted. [B] Neurite length/cell: ratio between total neurites length and number of cells counted. The data sets are the mean $\pm \mathrm{SE}$ of three independent experiments. Data were analyzed by One way ANOVA and Bonferroni test for multiple comparison (Values compared to control cells vs NGF and vorinostat; NGF and vorinostat treated cells vs inhibitor in combination with vorinostat and NGF. * $\mathrm{P}<0.05$, ** $\mathrm{P}<$ 0.001 indicate significant difference compared to control. 

GW441756

As vorinostat mediated neurite outgrowth was attenuated in presence of TrkA inhibitor, we also checked, if GW441756, the selective inhibitor of TrkA, also effects vorinostat induced ERK1/2 phosphorylation. NS-1 cells $\left(2.5 \times 10^{5}\right)$ were seeded onto collagen I coated flask and allowed to adhere for 24 hours. The cells were treated with vorinostat $(1$ and $2.5 \mu \mathrm{M})$ with and without GW441756 inhibitor for 3 hours. Since the treatment was for shorter duration up to 3 hours only so higher dose of $2.5 \mu \mathrm{M}$ vorinostat could also be tested. Cells were harvested, lysates were prepared and western blotting was done using antibody against anti-pERK. There was significant activation of ERK at both the doses of vorinostat $(1 \& 2.5 \mu \mathrm{M})$ tested and this activation of ERK in terms of ERK phosphorylation was significantly abolished in the presence of TrkA inhibitor (GW441756) (Figure 6 A \& B). This clearly demonstrates the involvement of upstream kinase TrkA in vorinostat-mediated ERK phosphorylation.

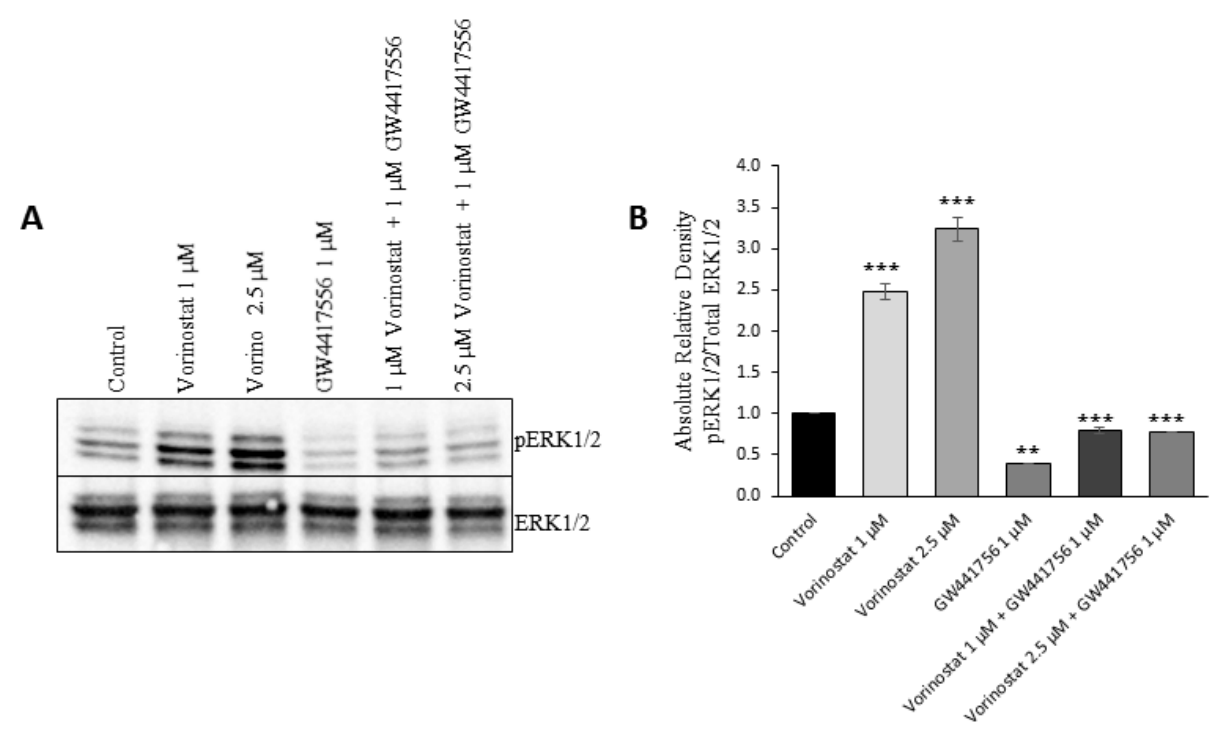

Figure 6. Effect of TrkA inhibitor GW441756 on vorinostat and NGF mediated ERK phosphorylation. A) NS-1 cells were treated with vorinostat $(1$ and $2.5 \mu \mathrm{M})$ and NGF (2.5 ng $\left.\mathrm{mL}^{-1}\right)$ with and without GW441756 $(1 \mu \mathrm{M})$ for 3 hours. The blots were probed with antipERK.1/2 antibody. Vorinostat mediated activation of ERK1/2 phosphorylation (pErk) was abolished in presence of GW441756. Total ERK levels were checked using ERK 1/2 antibody. B) Bar graph represents the densitometric analysis of immunoblots. $X$ axis represents treatments and $\mathrm{Y}$ axis represents the ratio of absolute relative density of $\mathrm{pERK}$ to the total ERK. The data sets are the mean $\pm \mathrm{SE}$ of two biological replicates from two independent experiments (values compared to control vs vorinostat $1 \mu \mathrm{M}$ and $2.5 \mu \mathrm{M}$, vorinostat $1 \mu \mathrm{M}$ and $2.5 \mu \mathrm{M}$ Vs GW441756 + vorinostat 1 and $2.5 \mu \mathrm{M}$ respectively). $* \mathrm{P}<0.05$, ** $\mathrm{P}<0.001$, *** $\mathrm{P}<0.0001$ indicate significant differences and ns indicates non-significant difference. 


\subsection{Vorinostat induces acetylation of histones $\mathrm{H} 3$ and $\mathrm{H} 4$.}

To determine whether changes in histone acetylation also occur during vorinostat induced differentiation of NS-1 cells and we compared changes in acetylation of histone H3 and H4 in untreated and vorinostat treated NS-1 cells. To detect acetylation of histone H3 and H4, NS-1 cells were treated with vorinostat $(1$ and $2.5 \mu \mathrm{M})$ for 24 hours. Protein lysates were prepared from treated and untreated cells and analyzed by western blot using antibodies specific for acetylated histones $\mathrm{H} 3$ and H4. Prominent hyperacetylation of histones H3 and H4 was observed in vorinostat treated NS-1 cells as compared to untreated cell, which did not show any level of acetylation of histones $\mathrm{H} 3$ and $\mathrm{H} 4$ (Fig 7). To confirm that changes in acetylation of histones H3 and $\mathrm{H} 4$ were due to change in level of acetylation and not because of changes in overall histone levels, we also performed western blot analysis with antibodies against total histones. (Fig 7) The steady state level of histones $\mathrm{H} 3$ and $\mathrm{H} 4$ remained same in both untreated and vorinostat treated cells.
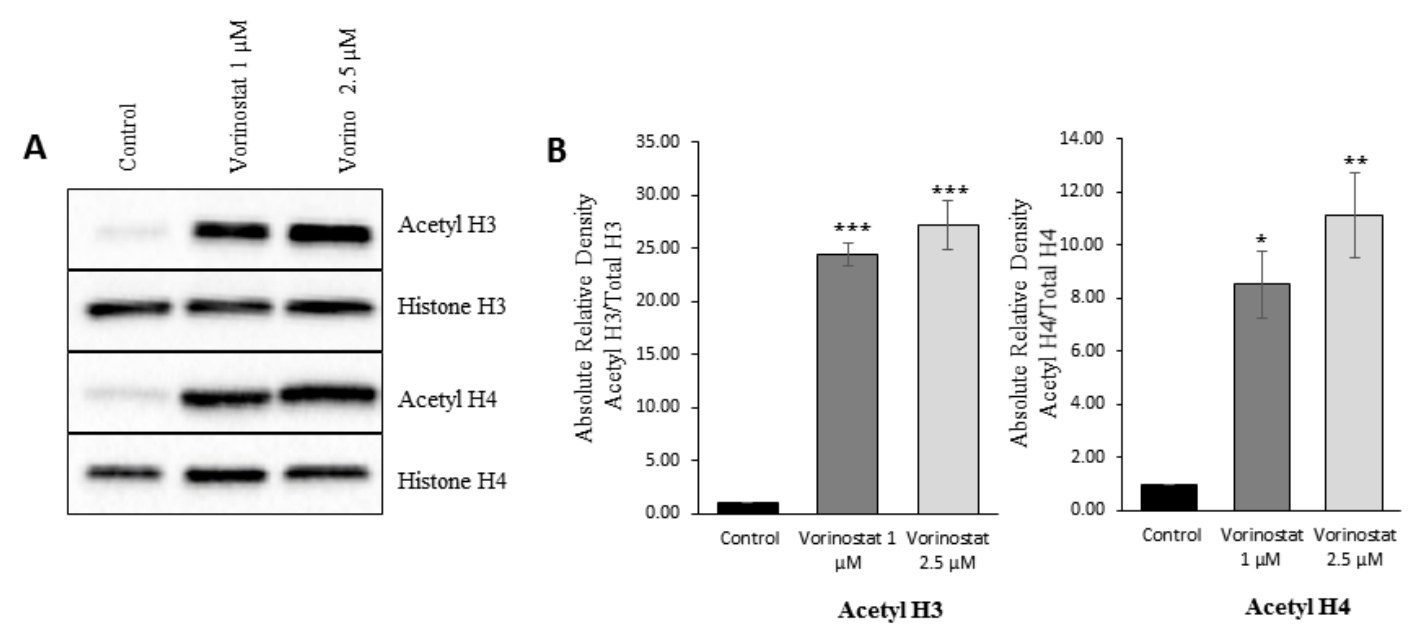

Figure 7. Vorinostat induces acetylation of histone $\mathrm{H} 3$ and $\mathrm{H} 4$ at 24 hour. A) NS-1 cells were treated with $1 \mu \mathrm{M}$ and $2.5 \mu \mathrm{M}$ vorinostat for 24 hours. Cell extracts were prepared and $20 \mu \mathrm{g}$ protein of the lysates were immunoblotted with anti-acetyl-histone H3 (Lys 9) and acetylhistone H4 (Lys 8) antibodies. Total histone levels were checked with antibody against histone H3 and histone H4. B) Bar graph represents the densitometric analysis of immunoblots. X axis represent treatments and $\mathrm{Y}$ axis represents the ratio of absolute relative density of acetyl- $\mathrm{H} 3$ to the total histone $\mathrm{H} 3$ and acetyl- $\mathrm{H} 4$ to total $\mathrm{H} 4$. The data sets are the mean $\pm \mathrm{SE}$ of two biological replicates from two independent experiments (values compared to control Vs vorinostat $1 \mu \mathrm{M}$ and $2.5 \mu \mathrm{M})$. * $\mathrm{P}<0.05$, ** $\mathrm{P}<0.001$, *** $\mathrm{P}<0.0001$ indicate significant differences and $\mathrm{ns}$ indicates non-significant difference.

\subsection{Vorinostat induces hyperacetylation of $\alpha$-tubulin}


To determine whether changes in acetylation of $\alpha$-tubulin also occur in vorinostat treated NS-1 cells, the cell cutures were treated with vorinostat for 8 hours and 24 hours and then cell lysates were probed with antibodies against acetyl- $\alpha$-tubulin (lys 40). At 8 and 24 hours, vorinostat $2.5 \mu \mathrm{M}$ significantly produced hyperacetylation of $\alpha$-tubulin as compared to untreated cells (Figure 8). Total $\alpha$-tubulin levels were also checked. The level of total $\alpha$-tubulin was unchanged in both treated as well as untreated cells.
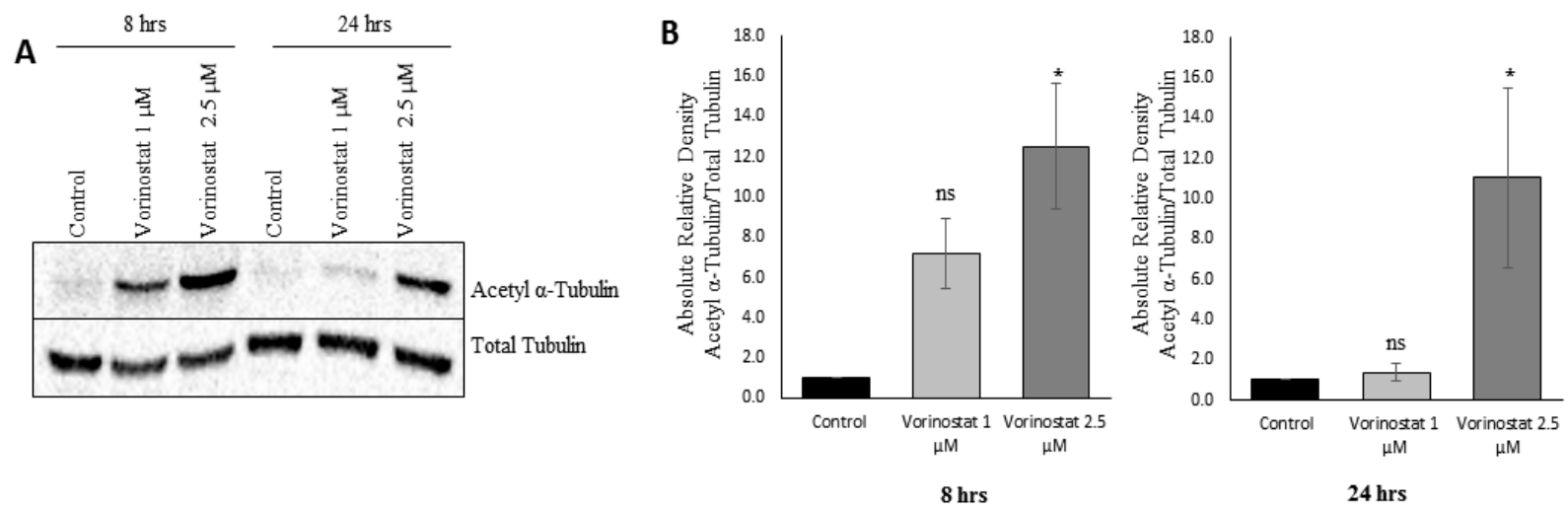

Figure 8. Vorinostat induces acetylation of $\alpha$-tubulin. NS-1 cells were treated with 1 and $2.5 \mu \mathrm{M}$ vorinostat for 8 hours and 24 hours. A) Western blotting was done and samples were probed with anti-acetyl $\alpha$-tubulin (Lys 40) antibody. Vorinostat induced hyperacetylation of $\alpha$ - tubulin at 8 hours and 24 hours as compared to control. Total tubulin level was also checked with antibody against $\alpha$-tubulin. B) Bar graph represents the densitometric analysis of immunoblots. $\mathrm{X}$ axis represents treatments and $\mathrm{Y}$ axis represents the ratio of absolute relative density of acetyl- $\alpha$ tubulin to the total $\alpha$-tubulin. The data sets are the mean \pm SE of two biological replicates from two independent experiments (values compared to control Vs vorinostat 1 and $2.5 \mu \mathrm{M}$ for 8 hours and 24 hours ). ${ }^{*} \mathrm{P}<0.05$ indicates significant difference and ns indicates non-significant difference.

\subsection{Vorinostat induces hyperacetylation of $\alpha$-tubulin in-situ.}

The $1 \times 10^{5}$ NS-1 cells were seeded onto the Ibidi microchamber collagen IV coated 4 well plastic slide. The cells were allowed to adhere for 24 hours. Cells were treated with $1 \mu \mathrm{M}$ vorinostat and $2.5 \mathrm{ng} / \mathrm{ml} \mathrm{NGF}$ for 6 hours and were immunostained with a rabbit monoclonal antibody against acetyl $\alpha$-Tubulin (Lys40) (D20G3) XP®. NS-1 cells treated with vorinostat showed increased level of acetylated $\alpha$-tubulin in the cytoplasm as compared to untreated NS-1 cells (control) and NGF treated cells (Figure 9). This confirms that treatment with vorinostat leads to increase in acetylation of $\alpha$-tubulin in the cytoplasm of the NS-1 cells. 

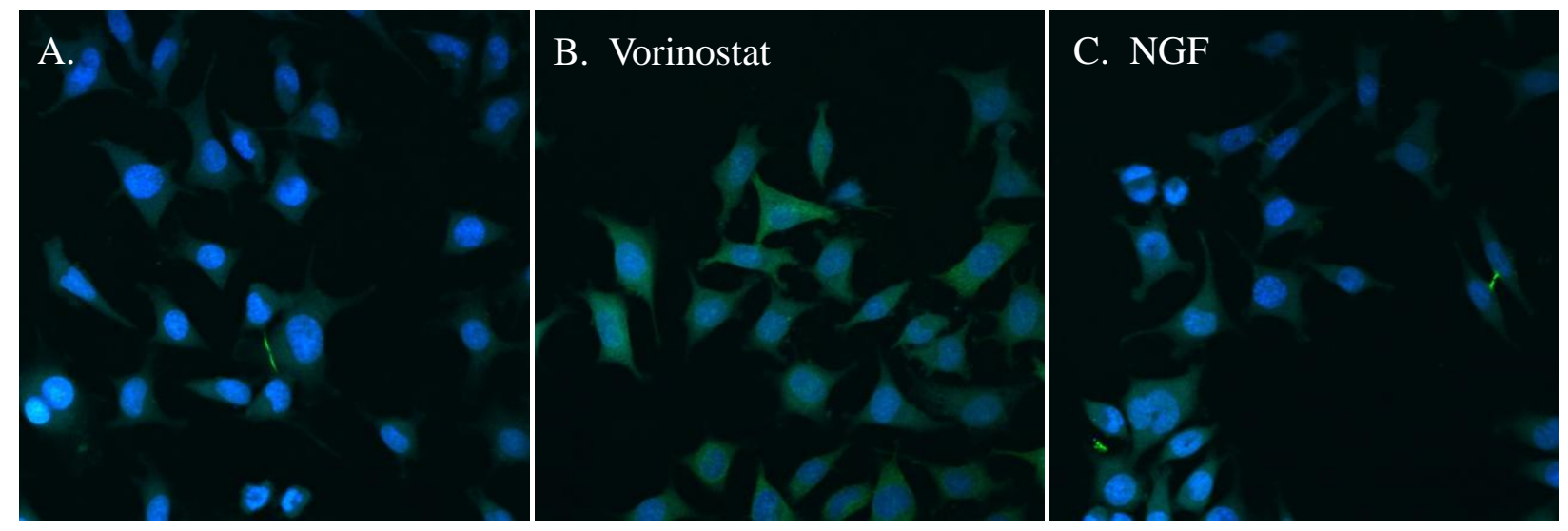

Figure 9. Immuno-localization analysis shows vorinostat stimulates acetylation of $\alpha$-tubulin in NS-1 cells. Treatment of NS1 cells with vorinostat $(1 \mu \mathrm{M})$ for 6 hours resulted in acetylation of $\alpha$-tubulin Lys 40. [A] Control cells with less or no staining for acetyl $\alpha$-tubulin (green). [B] Vorinostat treated cells with higher staining for acetyl $\alpha$-tubulin (green); [C] NGF $2.5 \mathrm{ng} \mathrm{mL}^{-1}$ treated cells with less or no staining for acetyl $\alpha$-tubulin. Cells were stained with DAPI (blue fluorescence) for nuclei. 


\section{Discussion}

Neuritogenesis or neuritic outgrowth is a fundamental process in the differentiation of neurons and plays an important role in neuronal development and formation of synapses (daSilva and Dotti, 2002). Neurodegenerative diseases occur as a result of progressive loss of structure and function of neurons (Ang et al., 2010). Neurotrophic actions and enhanced neuroplasticity and neurite outgrowth are important markers for neuroregeneration (Yoneyama et al., 2011). These processes are regulated by extrinsic and intrinsic determinants that affect gene expression and signal transduction pathways (Nakamura et al., 2008). Recent studies have reported neuroprotective effects of the HDACi (Zhang et al., 2012). The HDACs regulate expression of genes through deacetylation of histones and activation of transcription (Sterner and Berger, 2000).

The results presented in this study show that vorinostat independently induces neuritogenesis in NS-1 cells. Vorinostat has also been shown to confer acute neuroprotection in a recent study in mice (Sukumari-Ramesh et al., 2016). Attenuation of vorinostat-induced neurite outgrowth in presence of MEK1/2 inhibitor, U0126 suggests the involvement of the ERK pathway in vorinostat-induced differentiation. Attenuation of ERK phosphorylation mediated by vorinostat in presence of U0126 further confirms the involvement of MAPK pathway. We also tested the potential involvement of the PI3K pathway. Although neuritogenesis induced by vorinostat was attenuated in presence of PI3K inhibitor (LY294002). However, the attenuation was partial and less prominent as compared to that caused by the ERK inhibitors, U0126 and PD98059. The inhibitor of upstream kinase TrkA also attenuated vorinostat induced neurite outgrowth and also reduced the phosphorylation of ERK. This suggests role of activation of upstream kinase TrkA in the process of vorinostat mediated neurite outgrowth and activation of MAPK pathway. Thus neurotrophic action of vorinostat follows the mechanism similar to NGF (Vaudry et al., 2002). However, vorinostat did not further enhance neutrophic action of NGF on NS-1 cells. Activation of TrkA mediated neutrophic signaling pathways, the primary target for NGF action and proposed target for neurotrophic action of vorinostat, do not necessarily follow the linear response (Klesse and Parada, 1999; Vaudry et al., 2002; Lin et al., 2007). This may explain lack of synergy or additive response when vorinostat was tested in combination with NGF.

Vorinostat also induced hyperacetylation of histones H3 and H4 in NS-1 cells, which confirms ex vivo inhibition of HDAC activity by vorinostat in NS-1 cells at the concentrations tested for neurotrohic action. Increase in acetylation of histones and transcription factors in neurons has been shown to promote differentiation of neurons, whose molecular mechanisms are to some extent shared at some point in neurite outgrowth (Guab et. al., 2010). Vorinostat also induced hyperacetylation of $\alpha$-tubulin in NS-1 cells. Hyperacetylation of $\alpha$-tubulin is important for microtubule stabilization and transportation (Hubbert et al 2002). Hyperacetylation of $\alpha$ tubulin occurs due to pharmacological inhibition of HDAC6 that leads to increased acetylation of $\alpha$-tubulin (Zhang et.al 2003). HDAC class I and HDAC6 also could directly regulate neurite growth independently of epigenetic effects on transcription through deacetylation of $\alpha$-tubulin and other proteins (Hubbert et al., 2002 and Rivieccio et al., 2009).

Neurotrophin-mediated activation of TrkA receptor leads to activation of signaling pathways. These pathways are complex, involving a large number of signaling events and are associated 
with neurite extension /differentiation and survivals. These signaling pathways mainly function through protein phosphorylation cascades. Three major signaling pathways studied are (I) Ras/mitogen-activated protein kinase (MAPK) pathway, (II) Phosphatidylinositol-3 kinase pathway (PI3-K) /AKT pathway, and (III) Phospholipase C (PLC)-gamma pathway (Shimoke et al., 2009). Out of these, the most implicated pathway in controlling neuritogenesis/ differentiation is the MAPK cascade (Kaplan and Miller, 1997). Ras-extracellular signal regulated kinase (RAS-ERK) pathway plays an important role in neuronal differentiation (Enarson et al., 2002). Activation of small GTPase Ras through neurotrophin leads to signaling and transcription regulation, and plays an important role in neuronal survival and differentiation (Moodie et al., 1993). Activation of Ras leads to downstream activation of Raf1 and B-Raf, which in turn activates mitogen activated protein kinases MEK1 and MEK2. This further leads to phosphorylation of another set of MAP kinases, ERK1 and ERK2. MEK1 and MEK2 are dualspecificity protein kinases that function in the mitogen activated protein kinase (MAPK) cascade. The ERK signaling pathway controls cell growth, proliferation, differentiation and cell survival. NGF-induced neuritogenesis in PC12 cells occurs via sustained activation of extracellular signal regulated kinase through activation of TrkA (Marshall 1998; Rak-hit et al., 2001; Vaudry et al., 2002). NGF also activates phosphoinositidyl 3-kinase (PI3K) and its downstream effector kinase $\mathrm{PKB} / \mathrm{Akt}$, playing a role in neuronal survival. To assess the mechanism of vorinostat-induced neurite outgrowth, we studied the activation of ERK pathway given its accepted role in cellular differentiation (Enarson et al., 2002). As vorinostat independently induced neuritogenesis in NS1 cells like NGF, we hypothesize that vorinostat-mediated differentiation in NS-1 cells might occur via activation of ERK and/or PI3K pathways, similar to the activation by NGF. Both TrkA-associated pathways, namely MEK/MAPK and PI3K, were interrogated for vorinostatinduced neuritic outgrowth.

The results presented suggest that vorinostat promotes neuritogenesis in NS-1 cells via activation of the ERK Pathway. Blockade of vorinostat-induced differentiation, measured in terms of mean neurite length, neurites/cell and neurite length/cell by PD98059 and U0126 indicates that activation of ERK by MEK is required for this effect. In NS-1 cells, treatment with vorinostat leads to prominent activation of ERK. The results clearly demonstrate the activation of the ERK pathway in vorinostat-induced differentiation of NS-1 cells. We therefore hypothesized that vorinostat-mediated neurite outgrowth and activation of ERK may involve upstream kinase TrkA. The results show vorinostat mediated neuritogenesis as well as activation of ERK was reduced in presence of TrkA inhibitor, similar to that for NGF, suggesting the involvement of TrkA receptor in the activation of ERK pathway. However detailed mechanism by which vorinostat activates these pathways needs further investigation. Chen et.al, (2012) have reported that the mechanism by which vorinostat brings about neuronal differentiation and neuritogenesis in astroglial cells is possibly through binding with and activation of relevant neurotrophin receptor. However, in PC12 cells, signaling events and the precise mechanism for activation of ERK by vorinostat needs to be examined further. Vorinostat, as an anticancer agent in epidermal squamous cell carcinoma, has been shown to reduce cell survival by a attenuation of mTOR and ERK signaling pathways (Deepali et al., 2009). The phospho-extracellular signal regulated kinase was abruptly decreased at 24 hours, while phospho 38 MAPK was up regulated at 12 hours (Jenny et al., 2011). These reports indicate that the MAPK/ERK pathways show varying response to vorinostat depending on the target cells. Neurotrophin/TrkA signaling pathway has also been suggested as a promising therapeutic target for management of pain 
(Hirosi, et al., 2016), cancer (Demir et al., 2016), glaucoma (Wang et al., 2014). Valproic acid (VPA), an HDACi has been shown to be neuroprotective in primary astroglial cultures. VPA was found to induce expression of GDNF and BDNF, which in turn activated the ERK pathway in primary astroglial cultures (Chen et al., 2006 \& Wu et al., 2008). Yuan et al., (2001) have reported that VPA stimulated neurite outgrowth in SH-SY5Y cell culture by activating ERK pathway. These actions of VPA were similar to the effects exerted by other neurotrophic factors. The neurotrophic and neuroprotective effect of VPA, such as neuronal survival, neurite outgrowth and neurogenesis involve multiple mechanisms. Apart from HDAC inhibition and histone hyperacetylation, activation of ERK pathway (Hao et al., 2004; Yuan et al., 2001), microglial-mediated inflammation (Peng et al., 2005) and inhibition of pro-apoptotic factors (Kim et al., 2007) have been reported earlier for VPA. These data further supports our hypothesis that neurotrophic activity of vorinostat is mediated through activation of ERK pathway, histone hyperacetylation and acetylation of non-histone protein likes $\alpha$-tubulin. HDACi have shown significant impacts on neuronal, cardiomyocytic, and hepatic lineage differentiations. In most of the cases molecular mechanism for induction of differentiation was linked to regulation of transcription factors (Gaub et al., 2010).

In experimental models of disease such as amylotrophic lateral sclerosis, multiple sclerosis and Huntington's disease, neuroprotective effects of HDACi have been noted. However, precise mechanisms for their neuroprotective action are still obscure. Activation of the ERK pathway via TrkA receptor seems to be one of the mechanisms for induction of neuritogenesis by vorinostat in NS-1 cells. In contrast to the more rapid induction of ERK phosphorylation by NGF, vorinostat-induced phosphorylation of ERK was delayed, and was relatively transient. Which implies that vorinostat may be readily inactivated, or perhaps the mechanism of ERK activation by vorinostat is different from that of NGF. Vorinostat-induced neurite outgrowth appears to involve not only MEK, but also PI3K, since the neuritogenesis was inhibited in presence of LY294002, a PI3K inhibitor.

To the best of our knowledge, this is the first study showing role of the ERK pathway and upstream kinase TrkA in vorinostat-induced neurite outgrowth in NS-1 cells. This finding is in agreement with a number of previous studies, which have shown that HDACi exert neuroprotective \& neuritogenic effects via activation of ERK pathways. It would be important to investigate the possible role of other converging kinases, such as the cAMP and PKA-dependent pathways, in the downstream neuritogenic pathways or the pathways independent of MAPK/ERK activation. It would also be interesting to assess transcription dependent effect of vorinostat on NS-1 cell differentiation and regulation of expression of genes linked to the pathways of neuronal differentiation, neuritogenesis and neuroprotection.

In conclusion, this study demonstrates strong neurotrophic effect of vorinostat, and partly elucidates cellular and molecular mechanisms for vorinostat-mediated neurite outgrowth in NS-1 cells. Vorinostat induced neuritogenesis appears to involve activation of ERK pathways through TrkA receptor. Vorinostat induces hyperacetylation of $\alpha$-tubulin, which plays important role in neurite outgrowth /differentiation process. Hyperacetylation of histones $\mathrm{H} 3$ and $\mathrm{H} 4$ by vorinostat in NS-1 cells suggest significant role of transcription regulation of genes related to differentiation. Vorinostat is permeable to the blood brain barrier (Grant 2007 \& Lemonie 2010), which makes it an important drug candidate for targeting central nervous system. Vorinostat and 
other related HDACi with neurotrophic actions may be evaluated as promising candidates and potential therapeutic agents for treatment of neurodegenerative diseases and neuronal injuries by virtue of their ability to stimulate neuritic outgrowth. 


\section{Acknowledgements}

These studies are partly supported by the National Institute of General Medical Sciences (NIGMS), a component of the National Institutes of Health (NIH) (Grant \# P20GM104931) and USDA-ARS specific cooperative research agreement No. 58-6408-2-0009. The contents are solely the responsibility of the authors and do not necessarily represent the official view of NIGMS, NIH or USDA

\section{Authorship Contributions.}

Participated in research design: Shukla,S and Tekwani, B Conducted experiments: Shukla, S

Contributed new reagents or analytic tools: Shukla, S, Shariat-Madar, Z, Walker A and

Tekwani B

Performed data analysis: Shukla,S and Tekwani, B

Wrote or contributed to the writing of the manuscript: Shukla, S, Shariat-Madar, Z, Walker A and Tekwani B 


\section{References}

1. Ang ET, Tai YK, Lo SQ, Seet R, and Soong TW (2010). Neurodegenerative diseases: exercising toward neurogenesis and neuroregeneration. Front Aging Neurosci 2. pii: 25. doi: 10.3389/fnagi.2010.00025.

2. Bose P, Dai Y, and Grant S (2014). Histone deacetylase inhibitor (HDACi) mechanisms of action: Emerging insights. Pharmacol Ther 143:323-336.

3. Camelo S, Iglesias AH, Hwang D, Due B, Ryu H, Smith K, et al. (2005). Transcriptional therapy with the histone deacetylase inhibitor trichostatin A ameliorates experimental autoimmune encephalomyelitis. J Neuroimmunol 164:10-21.

4. Chen PS, Peng GS, Li G, Yang S, Wu X, Wang CC, et al. (2006). Valproate protects dopaminergic neurons in midbrain neuron/glia cultures by stimulating the release of neurotrophic factors from astrocytes. Mol Psychiatry 11:1116-1125.

5. Chen SH, Wu HM, Ossola B, Schendzielorz N, and Wilson BC (2012). Suberoylanilide hydroxamic acid, a histone deacetylase inhibitor, protects dopaminergic neurons from neurotoxin-induced damage. British journal of pharmacology 165: 494-505.

6. Chuang DM, Leng Y, Marinova Z, Kim HJ, and Chiu CT (2009). Multiple roles of HDAC inhibition in neurodegenerative conditions. Trends Neurosci 32: 591-601.

7. Craig AM, Banker G (1994). Neuronal polarity. Annul Rev Neurosci 17: 267-310.

8. da Silva JS, Dotti CG (2002). Breaking the neuronal sphere: regulation of the actin cytoskeleton in neuritogenesis. Nat Rev Neurosci 3:694-704.

9. Deepali K, Ritesh KS, Sandeep CC, Mary EB, Levy K,Craig AE, et al. ( 2013). Vorinostat an HDAC inhibitor attenuates epidermoid squamous cell carcinoma growth by dampening mTOR signaling pathway in a human xenograft murine model. Toxicology and Applied Pharmacology 266(2): 233-244.

10. Dijkmans TF, Van Hooijdonk LW, Schouten TG, Kamphorst JT, Vellinga AC, Meerman JH, et al. (2008). Temporal and functional dynamics of transcriptome during nerve growth factor induced differentiation. J Neurochem 105: 2388-2403.

11. Dotti CG, Sullivan CA, and Banker GA (1988). The establishment of polarity by hippocampal neurons in culture. J Neurosci 8:1454-1468.

12. Enarsson, M, Erlandsson, A, Larsson, H, and Forsberg-Nilsson, K. (2002). Extracellular Signal-Regulated Protein Kinase Signaling Is Uncoupled From Initial Differentiation of Central Nervous System Stem Cells to Neurons. Molecular cancer research 1(2): 147-154.

13. Falkenberg KJ, and Johnstone RW (2014). Histone deacetylases and their inhibitors in cancer, neurological diseases and immune disorders. Nat Rev Drug Discov doi: $10.1038 / \mathrm{nrd} 4360$.

14. Gardian G, Browne SE, Choi DK, Klivenyi P, Gregorio J, Kubilus JK, et al. (2005). Neuroprotective effects of phenylbutyrate in the N171-82Q transgenic mouse model of Huntington's disease. J Biol Chem 280:556-563. 
15. Demir IE, Tieftrunk E, Schorn S, Friess H, Ceyhan GO. (2016) Nerve growth factor \&amp; TrkA as novel therapeutic targets in cancer. S0304-419X(16)30040-3. doi: 10.1016/j.bbcan.2016.05.003.

16. Gaub P, Tedeschi A, Puttagunta R, Nguyen T, Schmandke A, and Di Giovanni S (2010). HDAC inhibition promotes neuronal outgrowth and counteracts growth cone collapse through CBP/p300 and P/CAF-dependent p53 acetylation. Cell Death Differ 17: 1392-1408.

17. Glaser KB (2007). HDAC inhibitors: clinical update and mechanism-based potential. Biochem Pharmacol 74: 659-671.

18. Grant S, Easley C, and Kirkpatrick P (2007). Vorinostat. Nat Rev Drug Discov 6:21-22.

19. Green LA, and Tischler A (1982). PC 12 pheochromocytoma cells in neurobiological research. Adv Cell Neurobiol 3:373-414.

20. Hao Y, Creson T, Zhang L, Li P, Du F, Yuan P, et al. (2004). Mood stabilizer valproate promotes ERK pathway-dependent cortical neuronal growth and neurogenesis. J Neurosci 24: 6590-2599.

21. Hildmann C, Riester D, and Schwienhorst A (2007). Histone deacetylases--an important class of cellular regulators with a variety of functions. Appl Microbiol Biotechnol 75:487497.

22. Hirose M, Kuroda Y, Murata E. NGF/TrkA Signaling as a Therapeutic Target for Pain. Pain Pract $16: 175-82$

23. Hockly E, Richon VM, Woodman B, Smith DL, Zhou X, Rosa E, et al. (2003). Suberoylanilide hydroxamic acid, a histonedeacetylase inhibitor, ameliorates motor deficits in a mouse model of Huntington's disease. Proc Natl Acad Sci USA 100: 2041-2046.

24. Hubbert C, Guardiola A, Shao R, Kawaguchi Y, Ito A, Nixon A, et al. (2002). HDAC6 is a microtubule-associated deacetylase. Nature 417:455-458

25. Jenny YS, Hsiuyi T, Lian Xu, Zachary H, Bryan C, Mariateresa F, et al. (2011). Vorinostat induced cellular stress disrupts the p38 mitogen activated protein kinase and extracellular signal regulated kinase pathways leading to apoptosis in Waldenström macroglobulinemia cells. Leukemia \& Lymphoma 52 (9):1777-1786.

26. Kaplan DR and Miller FD (1997). Signal transduction by neurotrophin receptors. Curr Opin Cell Biol 9: 213 - 221.

27. Kim HJ, Rowe M, Ren M, Hong JS, Chen PS, and Chuang DM (2007). Histone deacetylase inhibitors exhibit anti-inflammatory and neuroprotective effects in a rat permanent ischemic model of stroke: multiple mechanisms of action. Pharmacol Exp Ther 321: 892-901.

28. Kiryushko D, Berezin, V, and Bock E (2004). Regulators of neurite outgrowth: Role of cell adhesion molecules. Ann NY Acad Sci 1014: 140-154.

29. Klesse LJ, Parada LF (1999) Trks: signal transduction and intracellular pathways. Microsc Res Tech 45:210-216.

30. Lemoine M, and Younes A (2010). Histone deacetylase inhibitors in the treatment of lymphoma. Discov Med 10:462-470.

31. Lin B, Pirrung MC, Deng L, Li Z, Liu Y, Webster NJ (2007) Neuroprotection by small molecule activators of the nerve growth factor receptor. J Pharmacol Exp Ther 322:59-69. 
32. Longo FM, and Massa SM (2013). Small-molecule modulation of neurotrophin receptors: a strategy for the treatment of neurological disease. Nat Rev Drug Discov 12:507-525.

33. Riessland M, Ackermann B, Förster A, Jakubik M, Hauke J, Garbes L, et al. (2010). SAHA ameliorates the SMA phenotype in two mouse models for spinal muscular atrophy. Hum Mol Genet 19 (8): 1492-1506.

34. Marshall, CJ (1998). Signal transduction.Taking the Rap. Nature 392: 553-554.

35. Maruoka H, Sasaya H, Sugihara K, Shimoke, and Ikeuchi T (2011). Low-molecular-weight compounds having neurotrophic activity in cultured PC12 cells and neurons. J Bio Chem 150: 473-475.

36. Moodie SA, Willumsen BM, Weber MJ, and Wolfman A (1993). Complexes of Ras.GTP with Raf-1 and mitogen-activated protein kinase kinase. Science 260: 1658-1661.

37. More SV, Koppula S, Kim IS, Kumar H, Kim BW, and Choi DK (2012). The role of bioactive compounds on the promotion of neurite outgrowth. Molecules 17:6728-6753

38. Munno, DW, Woodin, MA, Lukowiak, K, Syed, NI, and Dickinson, PS (2000). Different extrinsic trophic factors regulate neurite outgrowth and synapse formation between identified Lymnaea neurons. J Neurobiol 44: 20-30.

39. Munster PN, Troso-Sandoval T, Rosen N, Rifkind R, Marks PA, and Richon VM (2001). The histone deacetylase inhibitor suberoylanilide hydroxamic acid induces differentiation of human breast cancer cells. Cancer Res 61(23):8492-7.

40. Nakamura T, Aoki K, and Matsuda M (2008). FRET imaging and in silico simulation: analysis of the signaling network of nerve growth factor-induced neuritogenesis. Brain Cell Biol 36:19-30. 22:

41. Peng GS, Li G, Tzeng NS, Chen PS, Chuang DM, Hsu YD, et al. (2005). Valproate pretreatment protects dopaminergic neurons from LPS-induced neurotoxicity in rat primary midbrain cultures: role of microglia. Brain Res Mol Brain Res 134:162-169

42. Petri S, Kiaei M, Kipiani K, Chen J, Calingasan NY, Crow JP, et al. (2006). Additive neuroprotective effects of a histone deacetylase inhibitor and a catalytic antioxidant in a transgenic mouse model of amyotrophic lateral sclerosis. Neurobiol Dispp 40-49.

43. Rakhit S, Pyne S, and Pyne, NJ (2001). Nerve growth factor stimulation of p42/p44 mitogenactivated protein kinase in PC12 cells: role of G (i/o), G protein-coupled receptor kinase 2, beta-arrestin I, and endocytic processing. Mol Pharmacol 60: 63-70.

44. Riessland M, Ackermann B, Forster A, Jakubik M, Hauke J, Garbes L, Fritzsche I, Mende Y, Blumcke I, Hahnen E, Wirth B (2010) SAHA Ameliorates the SMA phenotype in two mouse models for spinal muscular atrophy. Hum. Mol. Genet. 19: 1492-1506.

45. Rivieccio MA, Brochier C, Willis DE, Walker BA, Melissa AD, McLaughlin K, et al. (2009). HDAC6 is a target for protection and regeneration following injury in the nervous system. Proc. Natl. Acad. Sci. U.S.A. 106: 19599-19604

46. Schinder AF, Poo M (2000). The neurotrophin hypothesis for synaptic plasticity. Trends Neurosci 23: 639-645 
47. Shimoke K, Fukunaga K, Matsumura Y, Kudo M, and keuchi T (2009). Protection from ER stress-mediated apoptosis by the neurotrophins. Curr Topics in Biochem Res 11: 19-28.

48. Slingerland M, Guchelaar HJ, and Gelderblom H (2014). Histone deacetylase inhibitors: an overview of the clinical studies in solid tumors. Anticancer Drugs 25:140-149.

49. Sterner DE, Berger SL (2000). Acetylation of histones and transcription-related factors. Microbiol Mol Biol Rev 64: 435-459.

50. Sukumari-Ramesh S, Alleyne CH Jr, Dhandapani KM (2016) The Histone Deacetylase Inhibitor Suberoylanilide Hydroxamic Acid (SAHA) Confers Acute Neuroprotection After Intracerebral Hemorrhage in Mice. Transl Stroke Res 7:141-148

51. Takano M, Horie H, Iijima Y, Dezawa M, Sawada H, and Ishikawa Y (2002). Brain-derived neurotrophic factor enhances neurite regeneration from retinal ganglion cells in aged human retina in vitro. Exp Eye Res 74: 319-323.

52. Vaudry D, Stork PJ, Lazarovici P and Eiden LE (2002). Signaling pathways for PC12 cell differentiation: making the right connections. Science 29: 1648-1649.

53. Wang H, Wang R, Thrimawithana T, Little PJ, Xu J, Feng ZP, Zheng W (2014) The nerve growth factor signaling and its potential as therapeutic target for glaucoma. Biomed Res Int. 2014:759473. doi: 10.1155/2014/759473.

54. Westerink RH, Ewing AG (2002) The PC12 cell as model for neurosecretion. Acta Physiol 192:273-285.

55. Wiech NL, Fisher JF, Helquist P, Wiest O (2009) Inhibition of histone deacetylases: a pharmacological approach to the treatment of non-cancer disorders. Curr Top Med Chem. 9:257-271.

56. Wu JY, Niu FN, Huang R, and Xu Y (2008). Enhancement of glutamate uptake in 1-methyl4-phenylpyridinium-treated astrocytes by Trichostatin. A Neuroreport 19:1209-1212.

57. Xu K, Dai XL, Huang HC, and Jiang ZF (2011). Targeting HDACs: a promising therapy for Alzheimer's disease. Oxid Med Cell Longev 143269. doi: 10.1155/2011/143269.

58. Yang XJ and Seto E (2008). The Rpd3/Hda1 family of lysine deacetylases: from bacteria and yeast to mice and men. Nature Reviews Molecular Cell Biology 9 (3).: 206-218

59. Yoneyama M, Shiba T, Hasebe S, and Ogita K (2011). Adult neurogenesis is regulated by endogenous factors produced during neurodegeneration. J Pharmacol Sci 115: 425-432

60. Yuan PX, Huang LD, Jiang YM, Gutkind JS, Manji HK, and Chen G (2001). The mood stabilizer valproic acid activates mitogen-activated protein kinases and promotes neurite growth. J Biol Chem 276: 31674-31683

61. Zhang QL, Wang L, and Zhang YW (2009). The proteasome inhibitor bortezomib interacts synergistically with the histone deacetylase inhibitor suberoylanilide hydroxamic acid toinduce T-leukemia/lymphoma cells apoptosis. Leukemia 23:1507-1514

62. Zhang Y, Li N, Caron C, Matthias G, Hess D, Khochbin S, et al. (2003). HDAC-6 interacts with and deacetylates tubulin and microtubules in vivo. EMBO J 22:1168-1179

63. Zhang ZZ, Gong YY, Shi YH, Zhang W, Qin XH, Wu XW (2012). Valproate promotes survival of retinal ganglion cells in a rat model of optic nerve crush. Neuroscience 224:2829310 